\title{
A quick fix for crooked teeth - recent advancements in corticotomy-facilitated orthodontics
}

\author{
Janita Shah* \\ Dental Officer, Ministry of Health, Government of Seychelles, Republic in the Indian Ocean
}

\begin{abstract}
Over the years orthodontics has gained much popularity. Treatment initiated to correct functional disturbances is now being advocated to improve appearances and aesthetics, not only for children and adolescents, but for adults as well. The new challenge experienced by practitioners and researchers in the field of orthodontics, is obtaining swift results with minimal adverse effects and chances of relapse. In today's world, time is of the essence, and the current orthodontic treatment times remain a concern to most patients.

The advent of corticotomy-facilitated orthodontics as a predictable, albeit aggressive, method of dramatically accelerating orthodontic tooth movement and enhancing post-orthodontic treatment stability, has paved the way forward for clinicians to modify this approach and develop less invasive techniques. This article reviews the recent advancements in corticotomy-assisted orthodontics and hopes to encourage future research to further refine these techniques such that they are more patientcentred.
\end{abstract}

\section{Introduction}

Over the recent years, as a result of the emphasis placed on facial aesthetics and appearance by society, an increasing number of adults are undergoing orthodontic treatment with the aim of achieving beautiful smiles [1]. However, there are still a number of patients who are reluctant to seek orthodontic treatment, their primary concern being the prolonged duration of treatment $[2,3]$.

The duration of orthodontic treatment also poses a concern from a dental point of view; the predisposition towards root resorption [4-6], dental caries [7] and gingival recession [8] rising with an augmentation in treatment time.

Decades have been invested into research; involving the trial of biologically active substances which accelerate bone metabolism [9], the application of cyclic mechanical and electric forces across teeth fitted with fixed appliances [10-12], and the development of surgicallyfacilitated orthodontics, with the sole purpose of increasing the speed and efficiency of orthodontic treatment.

Utilising surgical techniques concomitantly with fixed orthodontic appliance therapy have proven to be clinically predictable and effective methods at accelerating orthodontic tooth movement and reducing the duration of treatment $[13,14]$. Current evidence suggests that bone exposed to surgical insults undergo a regional acceleratory phenomenon during healing; the decreased regional bone density and accelerated bone remodelling after injury is thought to be responsible for the acceleration of tooth movement during orthodontic therapy $[15,16]$.

\section{Periodontally accelerated osteogenic orthodontics (PAOO)}

The regional acceleratory phenomenon became the foundation for the development of a novel orthodontic modality; a multidisciplinary approach combining selective alveolar decortications, particulate bone grafting and the subsequent application of orthodontic forces. Periodontally Accelerated Osteogenic Orthodontics (PAOO) or Wilckodontics, introduced by the Wilcko brothers (2001), enabled teeth to be moved 2 to 3 times further in $1 / 3^{\text {rd }}$ to $1 / 4^{\text {th }}$ the time required for traditional orthodontics, as well as improved post-treatment stability and retention $[17,18]$.

This surgical approach improved on the technique of using corticotomies to facilitate orthodontic treatment, which although clinically resulted in an acceleration of orthodontic tooth movement by up to $66 \%$, gave rise to alveolar bone loss, thereby compromising the periodontal support of the target teeth. The ability of the procedure to increase the alveolar bone volume resulted in an augmentation of the bony support for the teeth and overlying gingiva, reduced the need for extractions, and allowed for a degree of facial reshaping [19,20].

However, drawbacks still remained. Most patients were discouraged by the invasiveness of the procedure, the post-operative swelling and pain that could be expected for several days, and the possibility of subcutaneous hematomas of the face \& neck associated with intensive corticotomies. Additionally, there was dissatisfaction amongst the orthodontists, as the chances of periodontal defects; slight interdental bone loss and loss of attached gingiva, still existed [21,22].

Correspondence to: Janita Shah, BDS, Dental Officer, Ministry of Health, Government of Seychelles, Republic in the Indian Ocean, Tel: +2482620110, E-mail: janita.shah16@gmail.com

Key words: alveocentesis, corticision, corticotomy-faciliated orthodontics, lasers, piezocision

Received: October 12, 2016; Accepted: October 27, 2016; Published: October 31, 2016 


\section{Monocortical tooth dislocation and ligament distraction technique (MTLDT)}

In an attempt to preserve the health of the periodontium whilst maximising the rapidity of orthodontic tooth movement, Vercellotti and Podesta (2007) invented and developed the Monocortical tooth dislocation and ligament distraction technique.

This procedure, more aptly known as a luxation manoeuvre, avoids the involvement of the periodontal ligament. Therefore, a significant reduction in post-operative bone resorption and ligament ankylosis was expected, in comparison to traditional and corticotomy assisted orthodontics, when the technique was used to treat deep bites, open bites and cross bites in eight patients.

The technique aimed to accomplish complex tooth movements in a relatively short period via two phases of treatment. The first phase involved the use of a piezoelectric saw to place corticotomy cuts laterally and apically to the tooth radix on the bone, after conventional flap elevation, and the immediate application of biomechanical force. This resulted in the rapid dislocation of the root and cortical bone as a unit, in the desired direction of tooth movement. Simultaneously, on the root surface opposite to the direction of tooth movement, there was a resultant rapid distraction of ligament fibres. During the osteogenic healing process that followed, the second phase of treatment was initiated, and the application of normal orthodontic biomechanics achieved the final tooth movement.

In comparison to traditional orthodontic approaches, the average duration of treatment in the mandible and maxilla was reduced by $60 \%$ and $70 \%$ respectively. All eight patients were followed up for more than a year after treatment, and no periodontal defects were observed [23].

A second study was carried out by Bertossi et al. (2012), where ten patients affected by different dental malformations were treated using the monocortical tooth dislocation and ligament distraction technique. Treatment time was shortened by up to $70 \%$ and no periodontal or gingival damage was observed, although all 10 patients experienced moderate oedema and pain [24].

\section{Corticision}

Park et al. (2006) developed the corticision technique whereby a reinforced scalpel is used as a thin chisel to separate the interproximal cortices transmucosally without reflecting a flap. According to Park, this flapless corticotomy technique is minimally invasive, and speeds up tooth movement by stimulating osteoblasts and bending alveolar bone that has been surgically separated.

The procedure involves the insertion of surgical blade interproximally and parallel to the occlusal plane $5 \mathrm{~mm}$ apical from the tip of the papilla. The blade is tapped with a mallet to a depth of approximately $8 \mathrm{~mm}$. The angle of the blade is then changed to approximately 45 degrees apically and the blade is tapped to a depth of $10-12 \mathrm{~mm}$. The goal is to cut the cancellous bone between the roots to $50 \%-75 \%$ of the root length. The blade is then removed and orthodontic forces are applied immediately. Every fortnight, the teeth are forcibly mobilized to induce minor trauma to extend the regional acceleratory phenomenon effect [25].

Kim et al. (2009) tested this innovative technique in cats. Histologic and histomorphometric studies performed on tissue specimens showed that corticision activated catabolic remodelling in the direction of tooth movement, showing extensive direct resorption of bundle bone with less hyalinisation and more rapid removal of hyalinised tissue. Corticision accelerated the anabolic remodelling as well; after 28 days of the experiment, the accumulated mean apposition area of new bone was observed to be 3.5 times higher in the experimental group than in the control group. This acceleration in bone remodelling resulted in acceleration of orthodontic tooth movement. No pathologic changes in the paradental tissues, or root resorption were revealed in the histologic findings following corticision $[26,27]$.

However, the technique has several drawbacks resulting in its unpopularity. It does not offer the benefits of bone and soft tissue grafting to correct inadequacies and reinforce the periodontium [28]. Additionally the repeated malleting can result in dizziness or benign paroxysmal positional vertigo, post-surgery, in real patients [29].

\section{Peizocision}

To overcome these disadvantages, Dibart et al. (2009) introduced piezocision; a minimally invasive technique to accelerate orthodontic tooth movement, combining piezosurgical cortical micro incisions with selective tunnelling that allows for hard- or soft-tissue grafting if required [30-32]. Due to their small size and precision, piezoelectric cutting inserts realize precise osteotomies without the risk of osteonecrosis, and the possibility of grafting gives this procedure the additional advantage of enhancing the periodontal support of the teeth [33].

The procedure demonstrated a similar clinical outcome when compared to the classic decortication approach but had the added advantages of being quick, minimally invasive, and less traumatic to the patient, therefore gaining greater patient acceptance [34]. An added benefit of this technique is that it can be used in selected cases with Invisalign to treat adults who would otherwise not pursue orthodontic treatment, leading to better aesthetic appearance and less treatment time [35].

\section{Minimally invasive rapid orthodontics (MIRO)}

In Dibart's description of the use of Piezocision to accelerate tooth movement, he emphasised on the careful placement of the cortical micro incisions, since irremediable damage could occur if they were placed in close proximity to the interproximal papilla or to the roots. Jofre et al. (2013) stated that Dibart's Piezocision technique was a blind approach as it lacked reference points to guide the surgical procedure and prevent inadvertent root damage. Therefore in an attempt to improve the safety and accuracy of the procedure they proposed a modification to the approach.

The minimally invasive rapid orthodontic method of accelerating tooth movement developed by Jofre et al. (2013), uses metal markers as radiographic references or guides for accurate placement of the incisions, and subsequently the corticotomy cuts. The metal guides are positioned in between each tooth, perpendicular to the main arch wire. Digital radiographs are then taken to ensure that the metal guides are not superimposed over the tooth roots. Once this is confirmed, incisions and piezoelectric corticotomy can be done using the metal guides as references, thus improving the precision of the procedure [36].

Cassetta and Giansanti (2016) further improved on this technique with the development of custom made, 3-D printed, computer-aided designed and computer-aided manufactured surgical templates. These surgical templates have slots designed to guide, at first, a scalpel blade and then a piezoelectric cutting insert, aiding the clinician in achieving 
a minimally-invasive, flapless piezoelectric corticotomy with minimal discomfort and surgical complications to the patient [37].

\section{Laser assisted flapless corticotomy}

For many years now, Erbium lasers have been widely used in various aspects of dentistry; from restorative dentistry to oral surgery, on both soft and hard tissues. When used on hard tissues, the Erbium laser energy heats up the water within the hard tissues. As the water is converted to steam, a mini-explosion occurs, and the hard tissue is "ablated" or removed. Ideally, the remaining hard tissue beneath should not be affected by the Erbium laser ablation, thereby allowing precise control and minimal damage to the surrounding tissue [38].

Due to the Erbium lasers' popularity in dentistry, dental researchers decided to test its application in corticotomy facilitated orthodontics, replacing the invasive bone cutting burs with the Erbium laser, which offers significant advantages over the conventional corticotomy technique; such as a noncontact intervention, absence of mechanical vibration, free and elaborate cut geometries and aseptic effects, making it a more patient centred alternative [39].

Seifi et al. (2012) carried out a study on rabbits to observe the effects of laser assisted flapless corticotomy (around the first right mandibular premolar) on the rate of orthodontic tooth movement. They concluded that the amount of orthodontic tooth movement in the experimental group was significantly greater than that of the control group. Within two weeks of the surgery, the tissues on the side with the corticotomy procedures appeared similar to the side without corticotomies. None of the rabbits showed clinical signs of swelling or displayed healing problems of the periodontal tissues beyond 10 days post-surgery. Data showed that laser assisted flapless corticotomy can enhance orthodontic tooth movement without jeopardizing the healing process of the soft tissue and the hard tissue [40].

Salman and Ali (2014) carried out a split-mouth study to evaluate the effect of laser assisted flapless corticotomy on the acceleration of maxillary canine retraction in 15 patients who required extraction of their maxillary first premolars followed by retraction of the canines as part of their orthodontic treatment plan. Flapless cortical decortications were done in the second stage of orthodontic treatment, on either side of the canine, using the erbium-doped yttrium aluminium garnet laser. The canines on the laser corticotomy side showed statistically higher mean value of retraction than their controls during the six week study period. Pulp vitality response and post-surgery gingival sulcus depth showed no significant difference between the pre-laser and post-laser surgery [41].

Savard (2016) also studied the effects of the laser-cision corticotomy procedure on the rate of orthodontic movement. Several advantages were noted in addition to the acceleration of orthodontic tooth movement. As the laser was used in a pre-contact mode, the patient felt no unpleasant sensation during the intervention, there was no reports of post-surgery pain, oedema or evidence of tissue necrosis and the gingiva healed rapidly without scarring, making it a very patient friendly procedure [42].

However, the lack of depth control of the lasers, which is currently limited to visual inspection, and the necessity for careful handling the necessity to continuously irrigate the surgical site so that it acts as heat sink [43], keep the energy settings as low as possible to enable cool ablation [44], and avoid keeping the laser beam in a fixed and contact mode to prevent charring and iatrogenic damage [45], are still technical limitations that need to be overcome.
Nevertheless with adequate operator training and experience, and with further developments in laser technology; special miniature laser systems [46], depth control feedback systems [47], and robotic navigation [48], laser assisted corticotomy may soon be endorsed as a completely safe and effective non-invasive method to speed up orthodontic tooth movement.

\section{Micro osteo perforations (Alveocentesis)}

Texeira et al. (2010) carried out animal studies to observe the effects of micro osteoperforations on bone metabolism and the rate of tooth movement. They documented a significant increase in the expression of inflammatory markers at the site of the shallow cortical bone perforations, which in turn resulted in an increase in the local activity of osteoclasts, responsible for the accelerated bone remodelling which followed and the subsequent increase in the rate and magnitude of tooth movement. They concluded that the micro perforations did not need to be in close proximity to the teeth to have such a significant impact on the rate of tooth movement, and as the perforations were small and limited - only 3 , the majority of the cortical bone remained intact [49].

Inspired by this study, and the potential of this micro invasive technique to effectively reduce the duration of orthodontic treatment duration, Propel Orthodontics invented and patented the Propel system, consisting of a ready-to-use sterile disposable device that can be used to place 2-3 micro perforations in the cortical bone through the gingival tissue, between each tooth undergoing orthodontic treatment. According to Propel Orthodontics, the procedure can be completed chair-side within minutes and does not require any advanced surgical training [50].

Mani Alikhani et al. (2013) decided to investigate the effects of the Propel system on the rate of orthodontic tooth movement in humans. Twenty adults with Class II Division 1 malocclusion were divided into control and experimental groups. The control group did not receive micro-osteoperforations, and the experimental group received microosteoperforations on one side of the maxilla. Both maxillary canines were retracted, and movement was measured after 28 days.

They observed that micro osteoperforations increased the rate of canine retraction 2.3 times compared to the control group; this was accompanied by a significant increase in the levels of inflammatory markers. Although, initially, patients reported mild discomfort locally at the spot of the micro osteoperforations, two weeks after the procedure had been initiated, little to no pain was experienced. Based on the results of their study, they concluded that micro osteoperforation is an effective, comfortable, and safe procedure to accelerate orthodontic tooth movement, with the potential to reduce treatment time by up to $62 \%$ when compared to traditional orthodontics [51].

However, as this was the first study investigating the micro osteoperforations method, there were certain issues that were not addressed, namely, the effect of micro osteoperforations on root resorption and possible long term complications of the procedure. Therefore, further studies and clinical trials are warranted not only to further investigate the procedure, but to also determine the precise depth and number of cortical perforations required to optimize the effect of micro osteoperforations on the rate of tooth movement.

\section{Conclusion}

Prolonged duration of orthodontic treatment is still one of the main reasons why patients are hesitant to undergo orthodontic 
treatment. With the discovery of corticotomy-assisted orthodontics, accelerated orthodontic treatment has become a reality. However, due to its aggressiveness, its clinical application has been limited. Developments and modifications to this approach, has given rise to less invasive, patient-centred techniques, such as the recent introduction of piezocision, which clinically, has resulted in better periodontal tissue response and esthetics.

Further clinical research is required to investigate and safely endorse a particular method of accelerating orthodontic tooth movement. However, the way has been paved forward for this new frontier in orthodontics, which will hopefully encourage more patients to seek orthodontic treatment.

\section{Acknowledgements}

The author owes a collective note of thanks to all of her professors and colleagues who have assisted \& supported her throughout her academic and clinical career.

\section{Competing interests}

None declared.

\section{References}

1. Khan RS, Horrocks EN (1991) A study of adult orthodontic patients and their treatment. Br J Orthod 18: 183-194. [Crossref]

2. Kazanca F, Aydayan C, Alkan A (2016) Patients' and parents' concerns and decisions about orthodontic treatment. Korean J Orthod 46: 20-26. [Crossref]

3. Oliveira PG, Tavares RR, Freitas JC (2013) Assessment of motivation, expectations and satisfaction of adult patients submitted to orthodontic treatment. Dental Press $J$ Orthod 18: 81-87. [Crossref]

4. Krishnan V (2005) Critical issues concerning root resorption: a contemporary review. World J Orthod 6: 30-40. [Crossref]

5. Brezniak N, Wasserstein A (1993) Root resorption after orthodontic treatment: Part 2. Literature review. Am J Orthod Dentofacial Orthop 103: 138-146. [Crossref]

6. Baumrind S, Korn EL, Boyd RL (1996) Apical root resorption in orthodontically treated adults. Am J Orthod Dentofacial Orthop 110: 311-320. [Crossref]

7. Tufekci E, Dixon J, Gunsolley J, Lindauer S (2011) Prevalence of white spot lesions during orthodontic treatment with fixed appliances. The Angle Orthodontist 81: 206210. [Crossref]

8. Petti S, Barbato E, Simonetti D'Arca A (1997) Effect of orthodontic therapy with fixed and removable appliances on oral microbiota: a six-month longitudinal study. New Microbiol 20: 55-62. [Crossref]

9. Diravidamani K, Sivalingam SK, Agarwal V (2012) Drugs influencing orthodontic tooth movement: An overall review. J Pharm Bioallied Sci 4: S299-303. [Crossref]

10. Kau CH (2011) A radiographic analysis of tooth morphology following the use of a novel cyclical force device in orthodontics. Head Face Med 7: 14. [Crossref]

11. Kau C, Kantarci A, Shaughnessy T, Vachiramon A, Santiwong P, et al. (2013) Photobiomodulation accelerates orthodontic alignment in the early phase of treatment. Progress in Orthodontics 14: 30.

12. Kolahi J, Abrishami M, Davidovitch Z (2009) Microfabricated biocatalytic fuel cells: a new approach to accelerating the orthodontic tooth movement. Medl Hypotheses 73 : 340-341. [Crossref]

13. Hoogeveen E, Jansma J, Ren Y (2014) Surgically facilitated orthodontic treatment: A systematic review. American Journal of Orthodontics and Dentofacial Orthopedics 145: S51-S64. [Crossref]

14. Hassan AH, Al-Fraidi AA, Al-Saeed SH (2010) Corticotomy-assisted orthodontic treatment: review. Open Dent J 4: 159-164. [Crossref]

15. Frost HM (1981) The regional accelerated phenomenon. Orthop Clin N Am 12: 725 726. [Crossref]

16. Frost HM (1983) The regional acceleratory phenomenon: a review. Henry Ford Hosp Med J 31: 3-9. [Crossref]
17. Wilcko M, Wilcko W, Pulver J, Bissada N, Bouquot J (2009) Accelerated osteogenic orthodontics technique: a 1-stage surgically facilitated rapid orthodontic technique with alveolar augmentation. J Oral Maxillofac Surg 67: 2149-2159. [Crossref]

18. Wilcko MT, Wilcko WM (2011) The wilckodontics accelerated osteogenic orthodontics (AOO) technique: An overview. Orthotown 4: 36-48.

19. Wilcko MT, Wilcko WM, Bissada NF (2008) An evidence-based analysis of periodontally accelerated orthodontic and osteogenic techniques: A synthesis of scientific perspectives. Semin Orthod 14: 305-316.

20. Wilcko WM, Wilcko T, Bouquot JE, Ferguson DJ (2001) Rapid orthodontics with alveolar reshaping: two case reports of decrowding. Int J Periodontics Restorative Dent 21: 9-19. [Crossref]

21. Bhat S, Singh V, Bhat M (2012) PAOO technique for the bimaxillary protrusion: Perioortho interrelationship. J Indian Soc Periodontol 16: 584. [Crossref]

22. Murphy K, Wilcko M, Wilcko W, Ferguson D (2009) Periodontal Accelerated Osteogenic Orthodontics: A Description of the Surgical Technique. J Oral Maxillofac Surg 67: 2160-2166. [Crossref]

23. Vercellotti T, Podesta A (2007) Orthodontic microsurgery: a new surgically guided technique for dental movement. Int $J$ Periodontics Restorative Dent 27: 325-331. [Crossref]

24. Bertossi D, Vercellotti T, Podesta A, Nocini PF (2011) Orthodontic microsurgery for rapid dental repositioning in dental malpositions. J Oral Maxillofac Surg 69: 747-753. [Crossref]

25. Park YG, Kang SG, Kim SJ (2006) Accelerated tooth movement by Corticision as an osseous orthodontic paradigm. Kinki Tokai Kyosei Shika Gakkai Gakujyutsu Taikai, Sokai 48.

26. Kim SJ, Park YG, Kang SG (2009) Effects of Corticision on paradental remodeling in orthodontic tooth movement. Angle Orthod 79: 284-291. [Crossref]

27. Murphy C, Kalajzic Z, Chandhoke T, Utreja A, Nanda R, et al. (2016) The effect of corticision on root resorption with heavy and light forces. The Angle Orthodontist 86: 17-23. [Crossref]

28. Keser E, Dibart S (2013) Sequential piezocision: A novel approach to accelerated orthodontic treatment. Am J Orthod Dentofacial Orthop 144: 879-889. [Crossref]

29. Peñarrocha-Diago M, Rambla-Ferrer J, Perez V, Pérez-Garrigues H (2008) Benign paroxysmal vertigo secondary to placement of maxillary implants using the alveolar expansion technique with osteotomes: a study of 4 cases. Int J Oral Maxillofac Implants 23: 129-132.

30. Dibart S, Sebaoun JD, Surmenian J (2009) Piezocision: a minimally invasive, periodontally accelerated orthodontic tooth movement procedure. Compend Contin Educ Dent 30: 342-344, 346, 348-350. [Crossref]

31. Dibart S, Keser E, Nelson D (2015) Piezocision ${ }^{\mathrm{TM}}$-assisted orthodontics: Past, present and future. Seminars in Orthodontics 21: 170-175.

32. Sebaoun JD, Surmenian J, Dibart S (2011) Accelerated orthodontic treatment with piezocision: a mini-invasive alternative to conventional corticotomies. Orthod $\mathrm{Fr} 82$ 311-319. [Crossref]

33. Vercellotti T, Nevins ML, Kim DM, Nevins M, Wada K, et al. (2005). Osseous response following resective therapy with piezosurgery. Int J Periodontics Restorative Dent 25 : 543-549. [Crossref]

34. Dibart S, Surmenian J, Sebaoun JD, Montesani L (2010) Rapid treatment of Class II malocclusion with piezocision: two case reports. Int $J$ Periodontics Restorative Dent 30: 487-493. [Crossref]

35. Keser EI, Dibart S (2011) Piezocision-assisted Invisalign treatment. Compend Contin Educ Dent 32: 46-48, 50-51. [Crossref]

36. Jofre J, Montenegro J, Arroyo R (2013) Rapid orthodontics with flapless piezoelectric corticotomies: First clinical experiences. International journal of odontostomatology 7: 79-85.

37. Cassetta M, Giansanti M (2016) Accelerating orthodontic tooth movement: A new, minimally-invasive corticotomy technique using a 3D-printed surgical template. Med Oral 21: 483-487. [Crossref]

38. Bader C, Krejci I (2006) Indications and limitations of Er:YAG laser applications in dentistry. Am J Dent 19: 178-186. [Crossref]

39. van As G (2004) Erbium lasers in dentistry. Dent Clin North Am 48: 1017-1059. [Crossref] 
40. Seifi M, Younessian F, Ameli N (2012) The Innovated Laser Assisted Flapless Corticotomy to Enhance Orthodontic Tooth Movement. J Lasers Med Sci 3: 20-25.

41. Salman L, Ali F (2014) Acceleration of canine movement by laser assisted flapless corticotomy: An innovative approach in clinical orthodontics. Journal of Baghdad College of Dentistry 26: 133-137.

42. Savard B (2016) Alveolar corticotomies with lasercision: a minimally invasive procedure in order to accelerate orthodontic treatments in adult patients. Rev Orthop Dento Faciale 50: 253-263.

43. Stübinger S, Ghanaati S, Saldamli B, Kirkpatrick C, Sader R (2009) Er:YAG laser osteotomy: preliminary clinical and histological results of a new technique for contactfree bone surgery. Eur Surg Res 42:150-156. [Crossref]

44. Romanos GE (1994) Clinical applications of the Nd:YAG laser in oral soft tissue surgery and periodontology. J Clin Laser Med Surg 12: 103-108. [Crossref]

45. Kimura Y, Yu DG, Fujita A, Yamashita A, Murakami Y, et al. (2001) Effects of erbium,chromium:YSGG laser irradiation on canine mandibular bone. $J$ Periodontol 72: 1178-1182. [Crossref]
46. Stübinger S (2010) Advances in bone surgery: the Er:YAG laser in oral surgery and implant dentistry. Clin Cosmet Investig Dent 2: 47-62. [Crossref]

47. Rupprecht S, Tangermann K, Kessler P, Neukam F, Wiltfang J (2003) Er:YAG laser osteotomy directed by sensor controlled systems. J Craniomaxillofac Surg 31: 337342. [Crossref]

48. Stopp S, Deppe H, Lueth T (2008) A new concept for navigated laser surgery. Lasers Med Sci 23: 261-266. [Crossref]

49. Teixeira C, Khoo E, Tran J, Chartres I, Liu Y, et al. (2010) Cytokine expression and accelerated tooth movement. J Dent Res 89: 1135-1141. [Crossref]

50. Nicozisis J (2012) Accelerated Orthodontics with alveocentesis. Princeton Orthodontics. Clin Orthod 19: 1-4.

51. Alikhani M, Raptis M, Zoldan B, Sangsuwon C, Lee Y, et al. (2013) Effect of microosteoperforations on the rate of tooth movement. Am J Orthod Dentofacial Orthop 144: 639-648. [Crossref]

Copyright: (C2016 Shah J. This is an open-access article distributed under the terms of the Creative Commons Attribution License, which permits unrestricted use, distribution, and reproduction in any medium, provided the original author and source are credited. 